\title{
Taiwan's Travel and Border Health Measures in Response to ZiKa
}

\author{
Li-Li Ho, Yu-Hui Tsai, Wang-Ping Lee, Szu-Tsai Liao, Li-Gin Wu, and Yi-Chun Wu
}

Zika virus has recently emerged as a worldwide public health concern. Travel and border health measures stand as one of the main strategies and frontline defenses in responding to international epidemics. As of October 31, 2016, Taiwan has reported 13 imported cases, 5 of which were detected through routine entry screening and active monitoring at international airports. This article shares Taiwan's disease surveillance activities at designated points of entry and travel and border health measures in response to Zika. The Taiwan government collaborates with its tourism industry to disseminate information about precautionary measures and encourages tour guides to report suspected individuals or events to activate early response measures. Taiwan also engages in vector control activities at points of entry, including targeting aircraft from countries where vector-borne diseases are endemic, implementing mosquito sweep measures, and collecting vector surveillance data. In future emerging and reemerging disease events, entry surveillance at designated points of entry may enable early detection of diseases of international origin and more rapid activation of public health preparedness activities and international collaboration. Taiwan will continue to maximize border and travel health measures in compliance with IHR (2005) requirements, which rely on continued risk assessment, practical implementation activities, and engagement with all stakeholders.

Keywords: Border health, Zika, Entry screening, Travel health, Fever screening, Surveillance

Z iKa, a flavivirus mainly transmitted by the Aedes mosquito, has been known to infect humans in parts of Africa and Asia, with limited cases reported before 2015. However, it is rapidly becoming a significant global public health concern, with at least 73 countries and territories reporting evidence of vector-borne Zika virus transmission. ${ }^{1}$ The first case of Zika reported in Taiwan occurred in
January 2016, after an infrared camera at an entry screening station detected mild fever in a man from Thailand upon his arrival at Taiwan Taoyuan International Airport. His infection with the Zika virus was confirmed through blood tests done by the Taiwan Centers for Disease Control (Taiwan CDC) laboratory. ${ }^{2}$ This case showed that establishing airport entry screening measures may be an effective

Li-Li Ho, MPH, is Senior Technical Specialist; Yu-Hui Tsai, MSc, is a Quarantine Officer; Wang-Ping Lee, MSc, is a Technical Specialist; Szu-Tsai Liao, MSc, is a Quarantine Officer; Li-Gin Wu, MSc, is a Technical Specialist; and Yi-Chun Wu, MD, MSc, PhD, is Division Director; all in the Division of Quarantine, Centers for Disease Control, Ministry of Health and Welfare, Taiwan, R.O.C.

(C) Li-Li Ho et al., 2017; Published by Mary Ann Liebert, Inc. This Open Access article is distributed under the terms of the Creative Commons Attribution Noncommercial License (http://creativecommons.org/licenses/by-nc/4.0/) which permits any noncommercial use, distribution, and reproduction in any medium, provided the original author(s) and the source are credited. 
method for identifying potential imported cases. ${ }^{3}$ It also raised the profile of Zika as an important public health concern not only in Taiwan but across Asia ${ }^{4}$ and provided the opportunity to revaluate the presence of the Zika virus in Southeast Asia.

On February 1, 2016, the World Health Organization (WHO) declared the cluster of microcephaly cases and other neurological disorders with possible Zika infection association a public health emergency of international concern (PHEIC). ${ }^{5}$ Taiwan immediately set up a Central Epidemic Command Center (TCECC) and announced 4 initial strategies for battling Zika virus infection: (1) overseas disease prevention, (2) travel and border health, (3) medical preparedness, and (4) vector surveillance and control. $^{6}$

Travel and border health measures are at the frontline during responses to international epidemic threats, before the detection of locally acquired cases or infected Aedes mosquitoes. The routine surveillance mechanisms and procedures used in Taiwan's travel and border health measures enable early detection of emerging diseases that could enter the country through points of entry. Existing activities were enhanced following the TCECC decision to focus on travel and border health as part of the official strategy to respond to Zika. Furthermore, entry screening procedures were extended to include continuous measures, starting with pre-travel education and ending with monitoring through the end of the potential incubation period. ${ }^{3,7}$ These efforts helped to accelerate national preparedness and community response, limit the impact of potential Zika infection introductions, and improve global and regional cooperation.

\section{ENTRY SCREENING}

After the SARS outbreak, the Taiwan CDC introduced fever screening and national laboratory monitoring of symptomatic passengers at international airports. ${ }^{3}$ Before entering the country, passengers are provided with a video asking them to self-report illness before their aircraft lands. If a passenger appears ill onboard, the crew is required to report the event immediately to port authorities, including the border quarantine officer. Further assessment may trigger onboard quarantine, aircraft site quarantine, or other measures.

Upon arrival, travelers undergo visual assessment, and infrared cameras are used to detect abnormal temperatures. If needed, an ear thermometer is used to recheck travelers' temperatures, and a quick in-person assessment is provided. Officials may also investigate travel and health history, symptoms, exposure, and other relevant factors. If the traveler fits the definition of a suspected case of imported dengue or Zika, a blood sample will be collected. Blood samples undergo the dengue NS1 antigen rapid test at international airports, and remaining blood and urine samples ${ }^{8}$ are sent to the Taiwan CDC's laboratory for further active monitoring for flaviviruses. A core value of Taiwan's traveler screening measures is to maximize efficiency and minimize travelers' inconvenience. The average assessment time is 30 to 40 minutes, which includes an in-depth interview and specimen collection before entering the country. These travelers are also provided with instructions to use insect repellent and other precautions (eg, safe sex guidance ${ }^{9}$ ). Furthermore, they are encouraged to seek medical care within 24 hours, and a local public officer will follow up on their health by phone. All symptomatic passengers' information is registered either by an ill-passenger health monitoring system or by the National Notifiable Disease Surveillance System (NNDSS) if they meet the conditions for a notifiable condition. Relevant control measures in the community will be implemented immediately to prevent further transmission (Figure 1).

From January to October 2016, Taiwan quickly screened a total of 21,083,404 inbound passengers. Of these passengers, 21,721 were identified as potentially ill through fever screening or passengers' self-reporting. Upon evaluation, 3,199 specimens were collected. A total of 5 laboratory-confirmed cases of Zika (4 symptomatic foreign laborers, 1 self-reporting citizen), 130 cases of dengue, and 4 cases of chikungunya were found. As Table 1 shows, the entry screening program from 2013 to 2016 contributed to the detection of total imported cases of dengue fever with rates of $41 \%$ to $48 \%$. All cases of chikungunya in Taiwan have been imported from overseas, and the majority of cases were detected from points of entry. The imported history can be traced back to 2006; the first chikungunya case was identified at Taoyuan International Airport and originated from Singapore, which had previously not reported any cases of the disease. ${ }^{10}$ Additionally, no Zika cases were found prior to 2015 , but the detection rate was $38 \%$ in 2016.

\section{Tourism Industry as a Partner}

Raising travelers' awareness of potential infectious disease risks is crucial, since prevention is preferable to treatment. Taiwan CDC issues travel health notices at weekly press conferences or more often as needed. To reach out to partners and the public, messages and education leaflets are printed and posted on an official website and distributed through traditional and social media. Many messages are targeted at pregnant women and those planning to become pregnant and recommend that these individuals postpone travel to affected areas. Health messages are also prominently displayed in Taiwan's international airport and seaports. In addition, there are 26 hospitals with travel medicine clinics, located in each city and county in Taiwan. These clinics also provide communicable disease prevention travel advisories. 


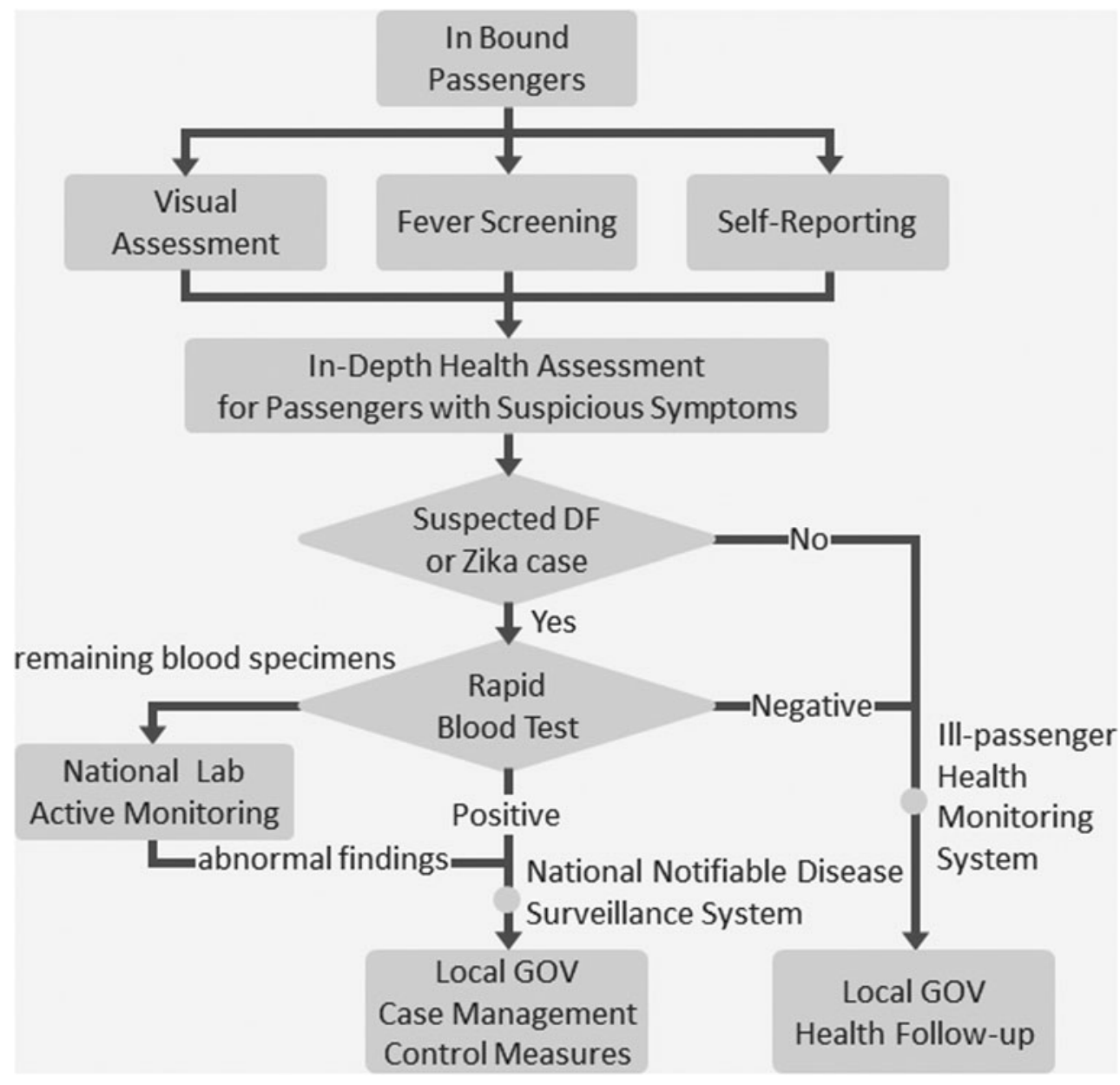

Figure 1. Entry Screening for Identifying Symptomatic Passengers

The tourism industry plays an important role in disease prevention. According to a recent investigation of Taiwanese travel behaviors, $34 \%$ of travelers join a tour group and $38 \%$ book tickets or hotels through an agency. ${ }^{11}$ Cooperation between the government and the tourism industry is targeted at raising industry and tourist guide knowledge regarding Zika virus and preventive measures, in order to provide tourists with the latest information about disease outbreaks in their destinations and to educate them on precautions in advance, throughout, and after travel. The tourism bureau requires tour guides to attend health courses and report suspected cases of communicable disease through the Taiwan CDC's toll-free hotline. Tour guides may be fined if they fail to report cases and rewarded if a reported case is confirmed.

As an example, during the lunar New Year public holiday in 2016, some Taiwanese tourists planned to travel to Central America and the Caribbean, an area with active

Table 1. Confirmed Cases Detected by Entry Screening, 2013-2016

\begin{tabular}{lcccc}
\hline & 2013 & 2014 & 2015 & Jan. to Oct. 2016 \\
\hline Inbound passengers & $19,072,276$ & $21,707,379$ & $23,601,215$ & $21,083,404$ \\
Ill passengers detected by entry screening & 12,924 & 15,280 & 17,779 & 21,721 \\
Specimens collected & 2,737 & 1,758 & 2,250 & 3,199 \\
Confirmed cases identified at points of entry/total imported cases $(\%)$ & & \\
& & & \\
Dengue fever & $115 / 263$ & $118 / 245$ & $155 / 365$ & $130 / 315$ \\
Chikungunya & $(44 \%)$ & $(48 \%)$ & $(42 \%)$ & $(41 \%)$ \\
Zika & $17 / 29$ & $4 / 7$ & $4 / 4$ & $(5 / 8 \%)$ \\
& $(59 \%)$ & $(57 \%)$ & $(100 \%)$ & $5 / 13$ \\
\end{tabular}


Table 2. Number of Mosquitoes Captured on Aircraft at 4 Designated Airports, 2013-2016

\begin{tabular}{|c|c|c|c|c|c|c|}
\hline \multirow[b]{2}{*}{ Year } & \multirow{2}{*}{$\begin{array}{c}\text { Number } \\
\text { of } \\
\text { Entry } \\
\text { Aircraft }\end{array}$} & \multirow{2}{*}{$\begin{array}{c}\text { Number } \\
\text { of } \\
\text { Aircraft } \\
\text { Sweeps }\end{array}$} & \multicolumn{2}{|c|}{ Culex Mosquito } & \multicolumn{2}{|c|}{ Aedes Mosquito } \\
\hline & & & $\begin{array}{c}\text { Number } \\
\text { of Aircraft (\%) }\end{array}$ & Captured & $\begin{array}{c}\text { Number } \\
\text { of Aircraft (\%) }\end{array}$ & Captured \\
\hline $2013^{a}$ & 82,605 & 568 & $14(2.46)$ & 16 & $0(0.00)$ & 0 \\
\hline 2014 & 134,487 & 895 & $8(0.89)$ & 8 & $0(0.00)$ & 0 \\
\hline 2015 & 139,644 & 1,524 & $38(2.49)$ & 50 & $0(0.00)$ & 0 \\
\hline Jan-Oct 2016 & 126,737 & 1,426 & $26(1.82)$ & 74 & $0(0.00)$ & 0 \\
\hline
\end{tabular}

${ }^{\mathrm{a}}$ Before 2013, it was regularly conducted in Taoyuan International Airport.

Zika virus transmission. The tourism bureau cooperated with the Taiwan CDC to provide information on precautions, monitor travelers, and provide refunds if pregnant women and those who were planning on becoming pregnant decided to postpone their travel. In total, 13 tour groups and 254 travelers (including tour guides) were monitored following travel. Although 1 person presented with a fever after returning to Taiwan, laboratory tests ruled out Zika infection.

\section{Vector Surveillance and Control Activities}

Although traveler health is one area of focus to reduce the potential for disease spread, Taiwan also conducts vector surveillance and control on the vehicles that transport travelers and cargo into the country. ${ }^{3}$ On February 22, 2016, the WHO provided recommendations regarding aircraft disinsection as a precautionary measure to control mosquitoes that spread the Zika virus based on countryspecific risk assessments. ${ }^{12}$

In Taiwan, trained and licensed professionals are stationed at points of entry and seasonally conduct vector surveillance at points of entry and the surrounding 400meter perimeters (or wider) according to WHO guidance. ${ }^{13}$ The frequency of surveillance and vector control activities can be increased based on previous results. Surveillance findings are provided to the port authorities to ensure that vector density remains below a pre-established baseline. A risk assessment is also completed according to the latest international epidemic data and previous surveillance records to determine if a mosquito sweep should be performed on inbound aircraft from countries with a high prevalence of vector-borne disease. In addition, vector surveillance and control activities also include adult mosquito sweeps and insecticide sprays on airplanes. The adult mosquito sweep takes 10 to 20 minutes per airplane and is primarily focused on overhead compartments, lavatories, and under-seat space without interfering with airline procedures. Any captured mosquitoes are sent to the Taiwan CDC's laboratory to undergo species identification and pathogen examination, and the airline is required to carry out vector control procedures and insecticide spraying.
The risk of transporting Zika-infected travelers through travel aboard ships is considered low in comparison to air travel. However, ships may pose a higher risk in introducing Zika-infected mosquitoes to the country. For example, used tires and ornamental plants requiring water during transport have previously led to the spread of mosquito vectors. ${ }^{13,14}$ In response to Zika, TCECC released an official letter requiring that ships implement vector control and clear breeding sites. Quarantine officers ensure that these activities have been completed during a ship sanitation inspection.

From January to October 2016, Culex quinquefasciatus adult mosquitoes $(N=74)$ were found on $26(1.82 \%)$ of 1,426 inbound aircraft from airports in middle and Southeast Asia. However, because Zika virus is primarily transmitted by the Aedes mosquito, captured adult mosquitoes were not tested further with pathogen RT-PCR. During the same period, inspection of 870 ships and seasonal vector surveillance showed that infectious risk remained below the previous baseline.

\section{Assessment of Taiwan's Points of Entry}

Taiwan has 7 designated points of entry (4 airports and 3 seaports). These points of entry meet the requirements of IHR 2005 core capacities and are able to cover over $95 \%$ of passenger and cargo movement to ensure national health and safety. ${ }^{15}$ These points of entry were established in 2 phases, which were supervised by the Homeland Security Office of Executive Yuan. The first phase (2010-2013) required that the highest traffic volume airport (Taoyuan International Airport) and seaport (Kaohsiung Port) meet IHR (2005) core capacities. ${ }^{16}$ Both of these ports completed a self-assessment and passed their international external evaluation, using the 95 assessment indicators and scoring system provided in the WHO tool. ${ }^{17}$ This successful experience was extended to another 5 points of entry in the second phase of the project (2014-2016). ${ }^{15}$ To ensure that these points of entry are able to maintain core capacities and coordination infrastructure, annual selfassessment is mandatory and an international external evaluation is required every 5 years. 
In 2016, Taiwan also initiated an external assessment of its national capacity using the Joint External Evaluation (JEE) tool. ${ }^{18}$ The indicator regarding point of entry core capacity was made up of 2 areas, one focused on routine capacities and another on effective response. Routine capacities include quarantine officers, medical evaluation units, established protocol for assessment and care of ill passengers, and referral to designated hospitals, if necessary. The system regularly undergoes exercises through real world events. Inspection programs and vector control also stand as important parts of routine capacities. In order to ensure effective response, protocols have been developed to evaluate public health risks at points of entry, including designated roles and responsibilities for multiple public agencies and private stakeholders. Taiwan routinely evaluates the effectiveness and shares lessons learned with internal stakeholders and the international community. The external assessment team gave Taiwan points of entry the highest score on both indicators. ${ }^{19}$

\section{Discussion}

As an island located in a subtropical zone with a warm and humid environment, Taiwan must remain vigilant against imported cases of vector-borne disease. While there is some debate about the effectiveness and opportunity cost of border entry screening, it has proven useful in border disease detection, especially when laboratory examination is included in the procedure. ${ }^{3,20-23}$ Entry screening measures may also provide an alternative policy response to tight travel restrictions. ${ }^{7,24}$ Although the core capacity of detection and response infrastructure is yet to be implemented in some countries, ${ }^{25}$ in future emerging and remerging disease events, entry surveillance at certain designated points of entry may enable early detection of diseases of international origin and more rapid activation of public health preparedness activities and international collaboration.

Entry screening reduces community transmission risk and provides opportunities for national prevention and preparedness efforts and risk communication. The following 2 examples highlight the success of Taiwan's border entry screening program.

Example 1: Before a community hospital detected the first imported Zika case in July 2016, 3 cases were found at international airports during an initial stage. As of October 31, 2016, Taiwan has no locally acquired Zika infections, but 13 imported cases have been identified, of which 38\% were identified by airport border screening. In one case, a citizen arriving in Taiwan self-reported Zika-related symptoms and was later confirmed to be infected by Zika by a Taiwan CDC laboratory diagnosis. ${ }^{26}$ Each year, more than 160,000 foreign workers arrive in Taiwan from Thailand, Indonesia, Vietnam, and the Philippines. The Taiwan CDC collaborates with the Ministry of Labour to provide Zika precaution education materials in a range of languages. Additionally, infected foreign laborers are able to receive the same medical treatment as Taiwanese citizens, and their right to work in Taiwan is not affected by their infection status, which promotes voluntary reporting of symptoms upon arrival. These border screenings have so far identified 4 imported Zika cases among laborers from Southeast Asian countries.

Example 2: In January 2016, an individual returning from China self-reported being in close contact with a confirmed case of H7N9 prior to arriving in Taiwan. The Taiwan CDC border quarantine officer provided education at the designated airport, and a local health officer monitored the traveler's health during the possible incubation period. ${ }^{27}$ These self-reporting cases are positive feedback of travel health education. The role of Taiwan citizens switched from receiver to reflector, and it also emphasized the image of border health quarantine as not only being prevention but first-hand protection.

In addition, travelers' health is a core mission of the Taiwan CDC. Important partners include travel medicine clinics, the tourism bureau, and the entire tourism industry. The industry is responsible for educating its members, as well as providing self-monitoring and reporting. This Zika epidemic response shows the importance of continued collaboration with key partners. Two of the confirmed imported Zika cases in Taiwan were members of the same tour group returning from Malaysia. Based on in-depth interviews, it was determined that both individuals received pre-travel education materials. These cases highlight that educational briefings and proper precautionary behavior cannot wholly eliminate the risk to travelers in Zikaaffected countries. Continued efforts to effectively communicate the risk of Zika infection in affected countries will help travelers make informed decisions about their health with respect to their travel plans. Another encouraging type of collaboration between the tourism industry and public health has been used before in the case of a diarrhea cluster, which was caused by norovirus occurring in 25 overseas tour groups organized by several agencies with similar schedules. Tour guides reported suspected cases in a timely manner and avoided a suspected restaurant that might have been the outbreak source based on the Taiwan CDC's investigation and recommendation; no additional case was reported and no community case was caused by the event. ${ }^{28}$

Furthermore, inbound aircraft from a number of specified countries have been required to undergo disinsection measures since February 2016. ${ }^{29,30}$ This requirement can increase airline industry operational costs and may cause delays or even flight cancellations. ${ }^{31}$ The International Civil Aviation Organization has proposed engaging with WHO to develop performance-based criteria to evaluate aircraft disinsection and relevant control methods. ${ }^{32}$ In Taiwan, there are routine monitoring measures and surveillance records for inbound aircraft arriving from countries where vector-borne disease is highly prevalent. Each year, the average adult mosquito capture rate is $0.89 \%$ to $2.49 \%$ in aircraft arriving from 
middle and Southeast Asia (Table 2). Taiwan uses surveillance records-based risk assessment to implement aircraft mosquito surveillance measures and provides results to airlines to ensure vector management standards are met. This risk assessment method may be a model practice for countries considering implementing a practical vector surveillance and control measure regarding aircraft disinsection.

Effective vector and Zika virus prevention measures, such as port sanitation surveillance, aircraft mosquito sweeps, and ship breeding site inspections, rely on the coordination of a cross-sectoral port sanitation taskforce. The port sanitation taskforce ${ }^{3}$ ensures that each stakeholder remains vigilant during public health threats and all the necessary control measures meet the core capacity requirements of IHR (2005).

\section{Conclusion}

Zika is an important international public health threat, and travel and border health measures have an important role in Taiwan's disease prevention strategies. Active surveillance efforts in points of entry to detect early-stage imported infections may help to accelerate national preparedness and response activities and improve global and regional cooperation. Travel and border health measures require cooperation and coordination with the tourism industry, port partners, airlines, multiple government agencies, local government, and international partners. Taiwan will continue to conduct risk assessment, adjust procedures, ensure practical implementation, and work in close collaboration with laboratory, local government, and other partners to achieve prevention, detection, and reduction of the international spread of disease without interference in international travel and trade.

\section{ACKNOWLedgments}

The authors express special thanks to Tara Kirk Sell for English editing and helpful suggestions. We would especially like to thank the points of entry taskforce and all colleagues in the Taiwan CDC for their commitment and contributions to the practice of travel and border health measures in Taiwan. Additionally, the authors are grateful to all of the partners across multiple agencies and relevant stakeholders for their cooperation.

\section{REFERENCES}

1. World Health Organization. Zika situation report. October 27, 2016. http://www.who.int/emergencies/zika-virus/situationreport/27-october-2016/en/. Accessed November 22, 2016.

2. Huang SE, Shu PY, Yang CH. A new reportable disease is born: Taiwan Centers for Disease Control's response to emerging Zika virus infection. J Formos Med Assoc 2016;115:223-225.
3. Chiu HH, Hsieh JW, Wu YC, et al. Maintaining human health at the border of Taiwan. Biosecur Bioterror 2014;12(6): 346-355.

4. Wiwanitkit S, Wiwanitkit V. Imported Thai patient with Zika virus to Taiwan: what else should be known and discussed? J Formos Med Assoc 2016;115:822.

5. World Health Organization. WHO statement on the first meeting of the International Health Regulations (2005) (IHR 2005) Emergency Committee on Zika virus and observed increase in neurological disorders and neonatal malformations. February 1, 2016. http://www.who.int/mediacentre/news/ statements/2016/1st-emergency-committee-zika/en/. Accessed November 22, 2016.

6. Taiwan Centers for Disease Control. Taiwan CDC activates agency-level command center to further step up efforts for ongoing Zika virus transmission and lists Zika virus infection as Category V Notifiable Infectious Disease [press release]. February 2, 2016. http://www.cdc.gov.tw/english/info. aspx?treeid=BC2D4E89B154059B\&nowtreeid=EE0A298 7CFBA3222\&tid=3876BD803A8D4AA2. Accessed November 22, 2016.

7. Cohen NJ, Brown CM, Alvarado-Ramy F, et al. Travel and border health measures to prevent the international spread of Ebola. MMWR Morb Mortal Wkly Rep 2016;65(3):57-67.

8. World Health Organization. Laboratory testing for Zika virus infection: interim guidance. March 23, 2016. http:// www.who.int/csr/resources/publications/zika/laboratorytesting/en/. Accessed November 22, 2016.

9. World Health Organization. Prevention of sexual transmission of Zika virus: interim guidance. Updated September 6, 2016. http://www.who.int/csr/resources/publications/zika/ sexual-transmission-prevention/en/. Accessed November 22, 2016.

10. Shu PY, Yang CF, Su CL, et al. Two imported chikungunya cases, Taiwan. Emerg Infect Dis 2008;14(8):1325-1327.

11. Taiwan Tourism Bureau. 2015 survey of travel by R.O.C. citizens. (Chinese version only) Appendix Table E5. http:// webpac.tbroc.gov.tw/bookDetail.do?id=24390\&Lflag=1. Accessed November 22, 2016.

12. World Health Organization. Aircraft disinsection for mosquito control. February 22, 2016. http://www.who.int/ihr/ ports_airports/zika-aircraft-disinsection/en/. Accessed November 22, 2016.

13. World Health Organization. Vector Surveillance and Control at Ports, Airports, and Ground Crossings. 2016. http://www. who.int/ihr/publications/9789241549592/en/. Accessed November 22, 2016.

14. EU SHIPSAN Act Joint Action. Interim guidance on maritime transport and Zika virus disease. Updated April 13, 2016. http://www.shipsan.eu/Home/Zikavirus.aspx. Accessed November 22, 2016.

15. Taiwan Centers for Disease Control. Report for assisted visit at designated PoE Taiwan 2015. May 2016. http://www. cdc.gov.tw/english/infectionreportinfo.aspx?treeid=384771910 4BE0678\&nowtreeid=77AF2770C4ACC1A3\&tid=BA9B107 CEEB91929. Accessed November 22, 2016.

16. Chiu HH, Hsieh JW, Wu YC, et al. Building core capacities at the designated points of entry according to the International Health Regulations 2005: a review of the progress and prospects in Taiwan. Glob Health Action 2014;7:24516. 
HO ET AL

17. World Health Organization. Assessment tool for core capacity requirements at designated airports, ports and ground crossings. 2009. http://www.who.int/ihr/ports_airports/PoE/ en/. Accessed November 22, 2016.

18. World Health Organization. Joint external evaluation tool: International Health Regulations (2005). 2016. http://apps. who.int/iris/handle/10665/204368. Accessed November 22, 2016.

19. Taiwan Centers for Disease Control. IHR JEE Report of Taiwan. 2016. http://www.cdc.gov.tw/english/infectionreport info. aspx?treeid $=3847719104 \mathrm{BE} 0678$ \&nowtreeid=77AF2770 C4ACC1A3\&tid=224CB92FB1DAA14B. Accessed January 9, 2017.

20. Cowling BJ, Lau LL, Wu P, et al. Entry screening to delay local transmission of 2009 pandemic influenza A (H1N1). BMC Infect Dis 2010;10:82.

21. Hale MJ, Hoskins RS, Baker MG. Entry screening for infuenza A(H1N1)pdm09 at Auckland International Airport, New Zealand. Emerg Infect Dis 2012;18(5):866-868.

22. Selvey LA, Antáo C, Hall R. Evaluation of border entry screening for infectious diseases in humans. Emerg Infect Dis 2015;21(2):197-201.

23. World Health Organization. Handbook for the Management of Public Health Events in Air Transport. 2015. http://www. who.int/ihr/publications/9789241510165_eng/en/. Accessed November 22, 2016.

24. Nuzzo JB, Cicero AJ, Waldhorn R, et al. Travel bans will increase the damage wrought by Ebola. Biosecur Bioterror 2014;12(6):306-309.

25. World Health Organization. IHR core capacities implementation status: points of entry. 2015. http://www.who. int/gho/ihr/monitoring/points_of_entry/en/. Accessed November 22, 2016.

26. Taiwan Centers for Disease Control. Taiwan confirms fifth imported Zika case in Taiwanese traveler who voluntarily reports himself upon arrival [press release]. August 12, 2016. http://www.cdc.gov.tw/english/info.aspx?treeid=BC2D4E89 B154059B\&nowtreeid=EE0A2987CFBA3222\&tid=94DFE 7A3751E6817. Accessed November 22, 2016.

27. Taiwan Centers for Disease Control. Taiwan CDC commends suspected $\mathrm{H} 7 \mathrm{~N} 9$ influenza patient for voluntarily notifying quarantine officer at airport upon arrival [press release]. January 12, 2016. http://www.cdc.gov.tw/english/info.aspx?treeid=BC2
D4E89B154059B\&nowtreeid=EE0A2987CFBA3222\&tid=41 14F9C939A544CA. Accessed November 22, 2016.

28. Wu HH, Su YS, Chen WC, et al. Investigation of acute diarrhea outbreak among Taiwanese group tourists in Korea, December 2013-January 2014. Taiwan Epi Bulletin 2014; 3(20): 174 .

29. European AIRSAN. Communication Platform (member access only). http://www.airsan.eu/Login/tabid/105/Default. aspx?returnurl=\%2fAIRSANNetwork\%2fCommunicationPlat form\%2fSearch.aspx. Accessed November 22, 2016.

30. National Business Aviation Association. Some countries requiring mosquito treatment for business aircraft in wake of Zika virus. February 16, 2016. https://www.nbaa.org/ops/ safety/20160216-some-countries-requiring-mosquito-treat ment-for-business-aircraft-in-wake-of-zika-virus.php. Accessed November 22, 2016.

31. Jordaan A. Fifth Pan European meeting of the ICAO Collaborative Arrangement for the Prevention and Management of Public Health Events in Civil Aviation (CAPSCA-EUR/ 05). October 2016. http://www2010.icao.int/EURNAT/ Other\%20Meetings\%20Seminars\%20and\%20Workshops/ CAPSCA\%20EUR/CAPSCA-EUR05/CAPSCA-EUR05\% 201-04\%20E.pdf. Accessed November 22, 2016.

32. International Civil Aviation Organization. Assembly Report on Agenda Item on October 31, 2016. http://ashsd. afacwa.org/docs/ICAOres2016.pdf. Accessed November 22, 2016 .

Manuscript received December 2, 2016;

revision returned January 17, 2017;

accepted for publication February 8, 2017.

Address correspondence to: Yi-Chun Wu, MD, MSc, PhD Division Director Division of Quarantine Taiwan $C D C$

No. 6, Linsen S. Road

Taipei City, Taiwan, R.O.C.

E-mail:wuyj@cdc.gov.tw 